\title{
First trimester prenatal diagnosis: earlier is not necessarily better
}

\author{
Judith A Boss University of Rhode Island, USA
}

\begin{abstract}
Author's abstract
In the past few years considerable attention has been given to a relatively new method of prenatal diagnosis known as chorionic villus sampling (CVS). Because CVS can be performed in the first trimester it is hailed by many as a significant advance over amniocentesis. What has not been as publicized, however, are the disadvantages of CVS and earlier prenatal diagnosis. The emotional costs of CVS in terms of the greater number of both spontaneous and selective abortions following CVS, the use of CVS for sex selection and, because of the greater social acceptability of first trimester abortion, the possibility of increased pressure on women to undergo prenatal diagnosis by health insurance companies, medical professionals and government agencies, all need to be weighed against the advantages of early prenatal diagnosis.
\end{abstract}

Second trimester amniocentesis is presently the most widely used method of prenatal diagnosis. In the past few years considerable attention has been given to a relatively new method of prenatal diagnosis known as chorionic villus sampling (CVS).

Unlike amniocentesis, which cannot be performed until the second trimester of pregnancy or very late in the first trimester, CVS can be carried out as early as eight to ten weeks' gestation. Also, while amniotic fluid needs to be cultured for three to four weeks, analysis of the chorionic villus sample can be carried out in twenty-four hours.

Because of this many medical professionals have enthusiastically endorsed the use of CVS over amniocentesis. 'It would be expected', concludes one group of prominent physicians and researchers:

'that the decision to interrupt the pregnancy in the second trimester would be more difficult than after CVS... . First trimester diagnosis allows privacy in reproductive decisions as the pregnancy is not yet physically evident and announcements of the pregnancy to family and friends may be delayed until prenatal evaluation is completed. Moreover, first

\section{Key words}

Abortion; amniocentesis; CVS; prenatal diagnosis. trimester termination of pregnancy is safer and probably less damaging emotionally than second ${ }^{\circ}$ trimester termination' (1).

These advantages have led to a significant shift in the past few years towards using CVS $(2,3)$. What has not been as publicized, however, are the $\vec{c}$ disadvantages of CVS and first trimester prenatal diagnosis. It is the purpose of this paper to point out $\mathbb{\mathbb { D }}$ and discuss some of these possible disadvantages.

\section{Accuracy}

One of the drawbacks of CVS is its lower accurat rate compared to the better than 99.5 per cent race for amniocentesis (4). This difference cannot be expected to improve substantially since CVS uses o cells from the placenta rather than directly utilizing 0 fetal cells for analysis as does amniocentesis. About $\cong$ 3.5 per cent of CVS procedures need to be repeated $\overrightarrow{\overrightarrow{0}}$ or followed up by amniocentesis because of failure to 3 obtain adequate material for analysis, maternal cell $\vec{F}$ contamination, and/or mosaicism - a condition where chromosomal abnormalities only appear in some of the cells $(5,6,7,8)$.

\section{Fetal loss}

Although CVS appears to pose little risk to the woman, there is a 3.2 per cent procedure-related fetal loss; with amniocentesis this rate is less than $1 \frac{7}{2}$ per cent $(4,5,6,7,9)$. Fetal loss appears to be highest with transcervical CVS $(10,11)$. Evans and N colleagues estimate that the procedure-related $N$ complication rate, in terms of fetal loss, is almost $51 / 2 \mathrm{~N}$ times higher for CVS than for amniocentesis, a risk ${ }_{\sigma}^{\omega}$ which they find 'acceptable' (3).

By undergoing CVS a woman accepts a one in을 thirty chance of miscarrying what is probably $\mathrm{a}_{\mathscr{\rho}}^{\Phi}$ normal fetus (3). In other words, if the difference in ${ }^{+}$ risk between CVS and amniocentesis is 2 per cent, $\frac{0}{0}$ an estimate which is probably on the low side, there $\overrightarrow{\mathbb{D}}$ will be as many as 66 normal fetuses lost for every $\frac{?}{\mathbb{D}}$ 100 abnormalities detected (11). Initially it was $\varrho$ conjectured that the procedure-related loss would drop as operators became more proficient in 
performing the procedure (6). However, this has not proved to be the case (9).

\section{Fetal damage}

Another disadvantage of CVS is a possible connection between CVS and malformations ranging from minor ones such as strawberry hemangiomas - reddish discoloration of areas of the skin - to major malformations such as limb reduction $(2,4,12)$. In a recent study of the pregnancy outcomes of 436 patients who underwent CVS, there were 391 surviving infants, 18 selective abortions, ${ }^{\star}$ and 27 fetal or neonatal deaths (10). Twenty-three of the last group involved chromosomally normal fetuses. Of the 394 fetuses and infants who were evaluated 3.3 per cent had major congenital anomalies, including four cases of limb reduction. All four cases of limb reduction had normal karyotypes.

A similar study found five cases of limb reduction among 289 pregnancies in which CVS had been carried out during the first trimester (13). These rates appear to be well above what would normally be expected.

\section{Higher rate of 'unnecessary' selective abortions}

The earlier stage at which CVS is performed significantly increases the chances of finding a fetal abnormality. The rate of spontaneous fetal loss after clinical diagnosis of pregnancy is $12-15$ per cent. Most of this loss is the result of chromosomal abnormalities in the young fetus or embryo (14). For example, more than 99 per cent of conceptions with Turner syndrome end in spontaneous abortion (15). And an estimated two-thirds of all fetuses with Down syndrome spontaneously abort during the first trimester (16).

After sixteen weeks, however, the rate of spontaneous loss is only 1 per cent. A test performed at eight weeks' gestation, consequently, will find over five times as many chromosomal abnormalities as a test done at sixteen weeks (17). This means that five times as many parents will have to suffer through the anguish of having to decide whether to abort their fetus. Thus, while the maternal mortality rate of second trimester abortions is higher (18), this factor is offset by the higher number of abortions that would be performed on women undergoing first trimester CVS.

\section{Psychological trauma of selective abortion}

Prospective parents are rarely prepared by the genetic counsellor for the extent of the psychological trauma experienced after a selective abortion. While there is no intention to minimize the tragedy and grief associated with losing a fetus through spontaneous abortion, the psychological effects of a miscarriage on parents are not as severe or longlasting as those of a selective abortion (19).

Because first trimester selective abortion is a relatively new phenomenon there have not, as yet, been any controlled studies to test the hypothesis that first trimester selective abortion is probably less damaging' (1) than an abortion performed later in the pregnancy. One cannot legitimately generalize from first trimester elective abortions, where the pregnancy itself is unwanted, to first trimester selective abortions where a wanted pregnancy is terminated.

Despite the widespread belief that the mere presence of 'choice' in the decision to have an abortion significantly reduces the anguish felt by the family, those who choose abortion because the fetus has a congenital disorder often suffer long-term grief which is almost identical to that experienced over the death of a newborn infant $(19,20,21)$. Unlike most miscarriages or stillbirths, where the loss is passive, selective abortion requires a deliberate choice. A miscarriage following CVS may also be perceived by the mother as her doing or 'fault', rather than as a miscarriage due to natural causes, because she chose to expose the fetus to risk by undergoing CVS. The ethical conflict of having to choose against life or for suffering, and the realization of one's own contribution to the ending of a life can lead to a loss of moral self-esteem and feelings of failure and guilt (22).

Another important difference between a stillbirth or death of a born child and the loss of a fetus is that the grief over the death of an aborted fetus is generally not recognized by society. Therefore, it is often harder for the parents to work through their feelings of loss following an abortion (23). It is possible that the 'privacy' of first trimester prenatal diagnosis and selective abortion may actually increase the unresolved 'disenfranchised' grief since so few people will know about the person's loss.

A recent study of the psychosocial sequelae of second trimester selective abortions found that they represented 'an emotionally traumatic major life event for both mother and father' (22). Even after two years 20 per cent of the women surveyed 'still complained of regular bouts of crying, sadness and irritability'. Twenty-eight per cent of the parents also wondered if the physician had made a wrong diagnosis. This percentage might be even higher among a group who had had an abortion following CVS, since the accuracy rate of CVS is lower than that of amniocentesis.

^The term 'selective abortion' is being used here to refer to an abortion where the parent(s) choose to terminate a wanted pregnancy because of a genetic disorder or some other undesirable characteristic of the fetus. 'Elective abortion' refers to the planned termination of an unwanted pregnancy. 
The emotional costs of CVS, therefore, must be weighed against the benefits of early diagnosis in light of the fact that the great majority of fetuses diagnosed with genetic disorders would have spontaneously aborted in the next month or two anyway. Because spontaneous abortion is less traumatic than a first trimester selective abortion, Hecklering and Verp calculate that second trimester prenatal diagnosis might be preferable in all but those cases where the fetus has at least a 50 per cent risk of carrying a genetic disorder (24).

\section{The fetal therapy justification}

One justification used for early prenatal diagnosis is that it allows physicians to diagnose and treat fetal disorders. There are efforts being made, it is pointed out, to develop in utero therapeutic procedures for correcting fetal abnormalities. One of the most promising is fetal stem-cell transplantation which involves grafting cells early in pregnancy while the fetus is still immunologically tolerant and before the disorder has become too developed (25). Also, with the improvement of high-resolution, real-time ultrasound, the success rate of intravascular blood transfusion for certain haemolytic (blood) disorders is now 85 per cent to 95 per cent (26).

The fetal therapy justification is very appealing to parents. In one study 185 women were asked to rate their attitude towards different types of prenatal diagnosis. The most favourable rating was given for 'ultrasound examination aimed at detecting treatable abnormalities' (27).

There is little doubt that relatively non-invasive technology whose primary purpose is to diagnosis treatable disorders would be warmly welcomed by parents and ethicists alike. However, this is not the reality associated with CVS. While new developments in fetal therapy hold out future hope for fetuses with disabilities, the present reality is that prenatal diagnosis rarely leads to fetal therapy. In fact, far more normal fetuses are killed as a result of the CVS procedure.

Even if therapy were possible, the availability of early prenatal diagnosis may make it easier and less costly simply to 'privately' abort the abnormal fetus and 'start again', rather than go through the greater trouble, uncertainty and expense of in utero surgery. Medical practitioners and pharmaceutical companies may also become less motivated to develop treatments for conditions that don't have to occur (28).

Research on cures for genetic disorders, whether in utero or after birth, may also be put aside in favour of selective abortion. This has already started happening to some extent. During the $1960 \mathrm{~s}$, for example, there were two to three times as many people working on a cure for Tay-Sachs disease than at present. The emphasis now is put on a prenatal diagnosis for Tay-Sachs disease, followed by abortion in the case of a positive diagnosis (29). Similarly, as soon as a prenatal diagnostic test for Huntington disease became available in the early 1980 s, 'funds began to disappear for research to find 0 a cure' (30). This trend might accelerate now that 7 first trimester prenatal diagnosis is available. Coupled with a decreasing amount of public moneys being used to assist the disabled, this could make $\mathbb{\mathbb { D }}$ continuing a pregnancy with a fetus who has a disabling disorder an option open only to more affluent parents.

It is generally conceded by the medical profession that the primary aim of prenatal diagnosis is the detection, and subsequent abortion, of abnormal fetuses. Because of the procedural risks to the fetus and the lack of effective methods of fetal therapy, '... with regard to most malformations, prenatal diagnosis is a rational activity only if abortion is seen as an acceptable alternative' (31).

\section{The 'reassurance' justification}

A more commonly used justification of early prenatal diagnosis is that it provides a means of $\frac{3}{\sigma}$ reassuring anxious parents that their fetus is normal. $\stackrel{\Phi}{-}$ However, while CVS might reassure parents that $\overrightarrow{0}$ their child does not have certain chromosomal ang $₫$ genetic disorders, one disadvantage of CVS is that unlike amniocentesis, it cannot be used to diagnos neural tube defects (NTDs) such as spina bifida and anencephaly. Although the majority of debilitating congenital disorders are the result of chromosomal and genetic anomalies, most of which can be detected by CVS, the incidence rate for NTDs is still significant at between 1.0 and 1.6 per 1,000 births -3 about the same as for Down syndrome, the most common major chromosomal disorder in newborns $(32,33)$. Also, unlike genetic disorders which are generally inherited, 95 per cent of all infants with NTDs are born to parents with no previous family history of the disorder (32).

Consequently, even if parents do have a negative test result from CVS and have no family history of NTDs they cannot rest assured that their fetus does not have an NTD until the second trimester when the alpha-fetoprotein (AFP) level can be tested using either amniotic fluid or maternal serum. Even then os AFP testing is only a screening tool rather than a $N$ diagnostic tool. Ultrasound, which can pick up most N cases of neural tube defects, is also not an effective $\underset{\sigma}{\sigma}$ diagnostic tool prior to 12 weeks $(34,35)$.

Barbara Rothman, in her book The Tentative $\frac{0}{\Phi}$ Pregnancy, maintains that it is the medical profession that has created a need for prenatal diagnosis for 0 'reassurance' by creating what she calls 'genetic $\overline{0}$ anxiety', thereby capitalizing on women's normal fear of having a 'defective', socially unacceptable $\frac{?}{\mathbb{D}}$ child - just as deodorant and mouthwash companies first had to create anxiety about socially unacceptable body odour before they could market their 
product (29). One cannot help but wonder if the battery of tests pregnant women are 'encouraged' to submit to for their own 'peace of mind' are not more to reassure the physicians that they will not be held legally liable should a 'defective' fetus get by undetected (36) and, in the case of first trimester CVS, that they will not have to perform late abortions and will thereby avoid the often great psychological trauma on the medical staff who have to perform late abortions $(37,38)$.

\section{Abortion for sex selection and minor disorders}

The greater social acceptability and 'privacy' of first trimester abortion may also lead to an increase of abortions for sex selection and for minor defects. In our society, where discrimination is based not only on physical and mental abilities, but on gender as well, female fetuses have a lower value (28). In a study of 2,278 women who had had CVS, it was found that CVS was being used more often than amniocentesis for reasons such as sex selection, despite policies against the use of prenatal diagnosis for sex selection at the centres which participated in that study (1).

In another study comparing CVS and amniocentesis, eight of the 1,928 women who had CVS later had an abortion for 'social reasons' (11). These eight made up 19 per cent of the total number of selective abortions. Of the 959 women who had undergone amniocentesis, none of the women had selective abortions for reasons other than chromosomal aberrations and sonographic abnormalities.

While approval of abortion for sex selection is low in the United States and most Western countries, the declining size of the American family, the preference for sons as first born or only children, and the emphasis on reproductive autonomy, are all contributing to a modification of this attitude. A 1975 survey of genetic counsellors in the United States found that, except in the case of sex-linked genetic disorders such as haemophilia or Duchenne muscular dystrophy, only 1 per cent would perform prenatal diagnosis for sex selection (37). By 1988 this figure had climbed to 62 per cent with the majority of geneticists giving as their primary reason 'respect for women's autonomy' (38).

The practice of withholding information about the gender of the fetus, unless it is medically relevant, is viewed by some as patronizing and an infringement on the parents' reproductive freedom of choice - a choice which should include deciding if the gender of the fetus constitutes too great a social burden for the parents. Other geneticists and feminists, on the other hand, argue that the use of prenatal diagnosis for sex selection is the 'original sexist sin ... because it makes the most basic moral judgement about the worth of a human being rest first and foremost on its sex' (39).
While many people claim that abortion choices are private rather than moral choices, it is hard to reconcile the medical profession's traditional commitment to egalitarian principles with the view that female feticide is a value-neutral choice. The family is not a private autonomous unit but rather a group existing within a particular social context, a context where being female constitutes an inferior status. If a woman is under pressure, whether religious or cultural, to have a son, should physicians yield to this pressure, thereby legitimating existing sex discrimination, or do they have a moral obligation to work for a more egalitarian society?

The principle of egalitarianism also raises the question of whether the worth of a human being should rest solely on her or his physical or mental abilities, especially where these disabilities are not lifethreatening or incompatible with sentient life. Women who have CVS seem to be more willing to seek an abortion for relatively minor disorders. For example, one study found that 97.6 per cent of women who had a positive result from CVS chose abortion, while only 78.1 per cent of those who had a positive result from amniocentesis opted for abortion (40).

The privacy of first trimester prenatal diagnosis and the relative ease of a first trimester abortion may eventually lead to demands for a 'custom-made child' where abortions are sought for fetuses who might have a genetic tendency towards obesity, or 'only' average intelligence and athletic prowess (41). 'The allure of a genetic test for a normal, or, in the future, an optimal baby', geneticist Marc Lappe cautioned us in 1973 when prenatal diagnosis was still in its infancy, 'threatens to reinforce an inexorable trend in Western society towards typecasting the less-than-optimal into categories for assortment and ultimate disposal' (42).

\section{Pressures to undergo prenatal diagnosis}

The availability of first trimester prenatal diagnosis may also increase the social pressure on women, who would otherwise prefer not to undergo the invasive medical procedure, to seek prenatal diagnosis. In a recent survey of 185 women who had just given birth to their first child, 30 per cent replied that they would rather not have CVS or amniocentesis during their second pregnancy. Only 36 per cent said they would definitely have one or the other during their second pregnancy (27).

'The social pressures to participate in screening programs and to terminate an affected pregnancy are considerable', notes child care and development specialist, Dr Josephine Green. 'Women may, as a result, experience considerable stress and find themselves acting against their own moral convictions' (43). Since the rate of chromosomal anomalies increases dramatically after age 30-35, so-called 'older women' would be particularly vulnerable to such pressures. The introduction of first trimester 
biochemical screening using maternal serum markers for disorders such as Down syndrome, while presently in the experimental stages $(44,45)$, could bring additional pressure to bear on women to undergo screening and, should the screening results be positive, to seek early prenatal diagnosis and possibly abortion.

The pressures brought to bear on women by the very availability of first trimester prenatal diagnosis may be similar to those created by screening programmes for such disorders as Tay-Sachs and sickle cell anaemia. Although these programmes were introduced to help parents in their family planning, the very availability of these programmes has led to pressure on those in high-risk categories to undergo screening, as well as to the stigmatization of carriers and social disapproval of marriage between carriers.

Bioethicist John Fletcher fears that, because of the cost-benefit advantage of prenatal screening, 'a climate of moral blame' may be cast around parents who do not comply. Indeed, suggestions have already been made that legislation should be passed to prevent the birth of children who fall below a 'minimum standard' (47). Because of the greater social acceptability of first trimester abortions, health insurance companies may also feel justified in withholding medical coverage from women who could have avoided the birth of a child with a 'costly' genetic disorder $(48,49)$.

Some physicians and ethicists express concern that justifying selective abortion of fetuses with genetic disorders on the basis of their potential financial or social burden to society may eventually lead to a policy of mandatory genetic screening and prenatal diagnosis $(46,50)$. Public approval of abortion for genetic disorders is significantly higher if the abortion is carried out during the first, rather than the second, trimester (51). This, in conjunction with the strong cultural bias in the Western world towards technological control of our environment and destiny, may make 'quality control' of our offspring not simply an option, but an obligation.

The state of California already requires that all pregnant women be 'offered' alpha-fetoprotein (AFP) testing. Those women who do not want AFP testing have to sign a refusal form (30). Should first trimester CVS become widely accepted similar requirements could be made regarding its availability to all pregnant women.

Incorporating prenatal diagnosis, and the issue of abortion, on the path to motherhood further removes control over one's pregnancy from women and places it even more in the hands of the medical profession and technocrats (29). Harvard biologist Ruth Hubbard writes in this regard that 'a woman who decides not to have prenatal tests or not to abort a fetus whom she knows has a disability takes on responsibility for the social, medical, and economic problems she and her family may experience as a result. It is incongruous to call that making a choice' (30).

\section{Conclusion}

In a consumer-oriented society that values quality products, quick fixes and 30-minute solutions to $\ddot{\vec{F}}$ major life crises, we must not forget to step back and $\stackrel{\overrightarrow{9}}{?}$ re-examine the 'the sooner the better' assumption. ? The advantages of first trimester CVS must be weighed against the cost of the greater number of $\frac{\bar{c}}{\overline{0}}$ procedure-related miscarriages and often unneces- $\mathbb{\complement}$ sary abortions that will be performed. Even for $\triangleq$ couples who are both carriers of deleterious autosomal recessive genes or, in the case of the women, an X-linked disorder, the choice of earlier $\vec{\omega}$ prenatal diagnosis is not as obvious as might be first thought. The cost of losing or harming a normal, very much wanted child as a result of CVS must be weighed against the burden of the extra two months of pregnancy before amniocentesis can be performed.

In addition, the very advantages in terms of $\vec{\overrightarrow{ }}$ privacy and the social acceptability of first trimester $\frac{9}{3}$ abortions may not only encourage the use of prenatal diagnosis for minor disorders and non-medical os reasons, such as sex selection, but could actually limit a woman's options by leading to policies that put pressure on women to undergo prenatal diagnosis and abortion of fetuses with defects. Earlier is not necessarily better.

fudith $A$ Boss, $M A, M S c, P h D$, is a Philosoph Lecturer in the Philosophy Department of the Universi of Rhode Island, Kingston, USA.

\section{References}

(1) Rhoads G, Jackson L G, Schlesselman S et al. The safety and efficacy of chorionic villus sampling for early prenatal diagnosis of cytogenetic abnormalities. New England journal of medicine 1989; 320: 609-617.

(2) Johnson A, Wapner R J, Davis G H, Jackson L G. Mosaicism in chorionic villus sampling: an associ- $\overparen{\Phi}$ ation with poor perinatal outcome. Obstetrics and gynecology 1990; 75: 573.

(3) Evans M I, Drugan A, Koppitch F C, Zador I E, ठ Sacks A J, Sokol R J. Genetic diagnosis in the first trimester: the norm for the 1990s. American journal of $\mathrm{O}$ obstetrics and gynecology 1989; 160: 1332-1339.

(4) Medical Research Council. European trial of chorionic $\frac{7}{2}$ villus sampling. Lancet 1991; 337: 1491-1499.

(5) Canadian Collaborative CVS-Amniocentesis Clinical $N$ Trial Group. Multirandomised clinical trial of $N$ chorion villus sampling and amniocentesis. Lancet $\mathcal{N}^{\circ}$ 1989; 1: 1-6.

(6) Bergman B, Claesson U, Mark J. Risk evaluation in a O small series of transabdominal chorionic villus

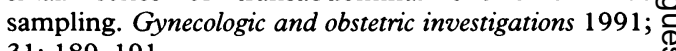
31: 189-191.

(7) Mitchell G, Loughman W, Epstein C, Halbasch G, $\stackrel{+}{+}$ Stephens J, Hall B. Prenatal genetic diagnosis in 3,000 amniocenteses. New England journal of medicine 1979; 300: 157-163.

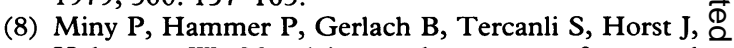
Holzgreve W. Mosaicism and accuracy of prenatal diagnosis after chorionic villus sampling and placental biopsies. Prenatal diagnosis 1991; 11: 581-589. 
(9) Meade T W, Grant A M. Chorionic villus sampling. British medical journal 1992; 304: 185-186.

(10) Burton B K, Schulz C J, Burd L I. Limb anomalies associated with chorionic villus sampling. Obstetrics and gynecology 1992; 79: 726-730.

(11) Smidt-Jensen S, Philip J. Comparison of transabdominal and transcervical CVS and amniocentesis: sampling success and risk. Prenatal diagnosis 1991; 11: 529-537.

(12) Kaplan P, Normandin J J, Wilson G N, Plauch H, Lippman A, Vekemans M. Malformations and minor anomalies in children whose mothers had prenatal diagnosis: comparison between CVS and amniocentesis. American journal of medical genetics 1990; 37: 366-370.

(13) Firth HV, Boyd PA, Chamberlain P, MacKenzie I Z, Lindenbaum $\mathrm{H}$, Huson $\mathrm{S} M$. Severe limb abnormalities after chorion villus sampling at 56-66 days' gestation. Lancet 1991; 337: 762-763.

(14) Boue J, Boue A, Lazar P. Retrospective and prospective epidemiological studies of 1,500 karyotyped spontaneous human abortions. Teratology $1975 ; 12: 11$.

(15) Rogers D, Shapiro L. X-linked disease and disorders of the sex chromosomes. In: Milunsky A, ed. Genetic disorders and the fetus. New York: Plenum Press, 1986: 349.

(16) Creasy M R, Crolla JA. The management of the patient having fetal diagnosis. Clinical obstetric gynaecology 1974; 1: 737-745.

(17) Simpson J L. Incident and timing of pregnancy losses: relevance to evaluating safety of early prenatal diagnosis. American journal of medical genetics 1990; 35: $165-173$.

(18) Tyler C. Epidemiology of abortion. Fournal of reproductive medicine 1981; 26: 463.

(19) Blumberg B, Golbus M, Hanson K. The psychological sequelae of abortion performed for a genetic indication. American journal of obstetrics and gynecology 1975; 122: 799-808.

(20) Powledge T. Toward a moral policy for sex selection. In: Bennett N, ed. Sex selection of children. New York: Academic Press, 1983: 40.

(21) Borg S, Lasker J. When pregnancy fails: coping with miscarriage, stillbirth and infant death. Boston: Beacon Press, 1981.

(22) White-Van Mourik M C S, Connor J M, FergusonSmith M A. The psychological sequelae of a second trimester termination of pregnancy for fetal abnormality. Prenatal diagnosis 1992; 12: 189-204.

(23) de Spelder L, Strickland A. The last dance. Palo Alto, CA: Mayfield Publishing Co, 1987: 218-219.

(24) Heckerling P S, Verp M S. Genetic risk and early versus late prenatal testing. Lancet 1991; 337: 363.

(25) Ferguson-Smith M A. Early prenatal diagnosis. Prenatal diagnosis 1991; 11:489-491.

(26) Grannum P A, Copel J A. Invasive fetal procedures. Radiologic clinics of North America 1990; 28: 217-226.

(27) Tymstra T J, Bajema C, Beekhuis J R, Mantingh A. Women's opinions on the offer and use of prenatal diagnosis. Prenatal diagnosis 1991; 11: 893-898.

(28) Lippman A. Prenatal genetic testing and screening: constructing needs and reinforcing inequities. American journal of law and medicine 1991; 17: 15-50.

(29) Rothman B. The tentative pregnancy. New York: Viking Press, 1986: 230.
(30) Hubbard R. Prenatal diagnosis and eugenic ideology. Women's studies international forum 1985; 8: 575.

(31) Carmenisch P. Abortion: for the fetus's own sake? Hastings Center report 1976; 6: 38.

(32) Milunksy A. The prenatal diagnosis of neural tube and other congenital defects. See reference (15): 453-520.

(33) Hsu L Y F. Prenatal diagnosis of chromosome abnormalities. See reference (15): 115-183.

(34) Romero R, Pilu G, Jeanty P, Ghidini A, Hobbins J. Prenatal diagnosis of congenital anomalies. Norwalk, CT: Appleton and Lange, 1988: 45.

(35) Nicolaides K H, Campbell S. Diagnosis of fetal abnormalities by ultrasound. See reference (15): 521-570.

(36) Furhman R, Black R. Pregnancy termination for genetic indications: the impact on families. Social work in health care $1984 ; 10: 17-34$.

(37) Fletcher J, Wertz D. Ethical aspects of prenatal diagnosis: views of US medical institutes of health. Clinical perinatology 1987; 30: 30.

(38) Wertz D, Fletcher J. Ethics and medical genetics in the United States. American journal of medical genetics 1988; 29: 323.

(39) Powledge T. Unnatural selection: on choosing children's sex. In: Holmes H, Hoskins B, Gross M, eds. The custom-made child? A woman centered perspective. Clifton, NY: Humana Press, 1981: 193-199.

(40) Verp M S, Bombard A T, Simpson J L, Elias S. Prenatal decision following prenatal diagnosis of fetal chromosome anomalies. American journal of medical genetics 1988; 29: 613-622.

(41) Holmes H, Hoskins B, Gross M. The custom-made child? $A$ woman centered perspective. Clifton, $\mathrm{NJ}$ : Humana Press, 1981.

(42) Lappe M. How much do we want to know about the unborn? Hastings Center report 1973; 3: 8.

(43) Green J M. Prenatal screening and diagnosis: some psychological and social issues. British journal of obstetrics and gynaecology 1991; 97: 1076.

(44) Johnson A, Cowchock F S, Darby M, Wapner D, Jackson L. First trimester maternal serum alphafetoprotein and chorionic gonadotropin in aneuploid pregnancies. Prenatal diagnosis 1991; 11: 443-450.

(45) Mancini G, Perona M, Dall'Amico D et al. Screening for Down's syndrome with maternal serum markers an experience in Italy. Prenatal diagnosis 1991; 11: 245-252.

(46) Fletcher J. Ethics and trends in applied human genetics. Birth defects 1983; 19: 143-158.

(47) Fletcher J. Our duty to the unborn. In: Fletcher J, ed. Humanhood: essays in biomedical ethics. Buffalo, NY: Prometheus Books, 1979: 123-124.

(48) Gostin L. Genetic discrimination: the use of genetically based diagnostic and prognostic tests by employers and insurers. American journal of law and medicine 1991; 17: 109.

(49) Baum R. Genetic screening: medical promise amid legal and ethical questions. Chemistry and engineering news 1989 Aug 7: 10-16.

(50) Johnson J, Elkins S. Prenatal treatment: medical and gene therapy in the fetus. Clinical obstetrics and gynecology 1988; 31: 409.

(51) Lamanna M A. Social science and ethical issues: the policy implications of poll data on abortion. In: Callahan S, Callahan D, eds. Abortion: understanding the differences. Hastings-on-the-Hudson, NY: The Hastings Center, 1984: 4-5. 